\title{
Automatic Fault Prediction of Wind Turbine Main Bearing Based on SCADA Data and Artificial Neural Network
}

\author{
Zhenyou Zhang \\ Renewables \& Utilities, Kongsberg Digital AS, Trondheim, Norway \\ Email: zhenyou.zhang@gmail.com
}

How to cite this paper: Zhang, Z.Y. (2018) Automatic Fault Prediction of Wind Turbine Main Bearing Based on SCADA Data and Artificial Neural Network. Open Journal of Applied Sciences, 8, 211-225. https://doi.org/10.4236/ojapps.2018.86018

Received: May 2, 2018

Accepted: June 25, 2018

Published: June 28, 2018

Copyright $\odot 2018$ by author and Scientific Research Publishing Inc. This work is licensed under the Creative Commons Attribution International License (CC BY 4.0).

http://creativecommons.org/licenses/by/4.0/

\section{c) (i) Open Access}

\begin{abstract}
As the demand for wind energy continues to grow at exponential rate, reducing operation and maintenance $(\mathrm{O} \& \mathrm{M})$ costs and improving reliability have become top priorities in wind turbine maintenance strategies. Prediction of wind turbine failures before they reach a catastrophic stage is critical to reduce the $\mathrm{O} \& \mathrm{M}$ cost due to unnecessary scheduled maintenance. A SCADA-data based condition monitoring system, which takes advantage of data already collected at the wind turbine controller, is a cost-effective way to monitor wind turbines for early warning of failures. This article proposes a methodology of fault prediction and automatically generating warning and alarm for wind turbine main bearings based on stored SCADA data using Artificial Neural Network (ANN). The ANN model of turbine main bearing normal behavior is established and then the deviation between estimated and actual values of the parameter is calculated. Furthermore, a method has been developed to generate early warning and alarm and avoid false warnings and alarms based on the deviation. In this way, wind farm operators are able to have enough time to plan maintenance, and thus, unanticipated downtime can be avoided and $\mathrm{O} \& \mathrm{M}$ costs can be reduced.
\end{abstract}

\section{Keywords}

Artificial Neural Network, SCADA Data, Wind Turbine, Automatic Fault Prediction

\section{Introduction}

Power production from renewable sources becomes more and more important globally to meet the increasing demand of power and reduce the effect of the energy production on the environments, such as water and air, ecological system 
and climate change. Wind power is one of the most developed renewable energy technologies worldwide with $432.491 \mathrm{GW}$ installed capacity at the end of 2015 [1]. It has overtaken hydro as the third largest source of power generation in the EU with a $15.6 \%$ share of total power capacity as seen in Figure 1 which has been increased remarkably from just tiny $2.4 \%$ in 2000 [2]. If the trend remains, it is no doubt that the target of $20 \%$ wind energy share of energy production in Europe will be met in 2020 [3] [4]. However, to achieve this target, the Levelised cost of wind energy still should be reduced further. Today, large wind turbines (2 - $10 \mathrm{MW}$ ) for both onshore and offshore from some wind equipment OEMs, such as Siemens and Vestas, are designed, tested and manufactured as economically viable alternatives to traditional fossil-fueled power generation. At the same time, the cost of wind energy has decreased sharply in last two decades which makes both onshore and offshore wind power more competitive than conventional power generation sources, such as coal and gas, and other renewable energy [5]. Even though, the cost of wind power production, especially for offshore wind power, need to be reduced further to make it more competitive to other resources. Operations and Maintenance $(\mathrm{O} \& \mathrm{M})$ has been estimated at up to $20 \%-30 \%$ of overall lifetime costs for energy [6] [7]. It is really making sense to reduce the $\mathrm{O} \& \mathrm{M}$ cost by reducing unanticipated downtime through an automatic condition monitoring system.

The best way to reduce the $\mathrm{O} \& \mathrm{M}$ cost of wind energy is to reduce downtime through online condition monitoring to enable the operators to plan maintenance action when and only when it needed. Wind turbines often operate in severe and remote environments which make the limitation of accessibility when the maintenance actions are needed. Therefore, unscheduled maintenance due to unexpected failures, even just small issues, can be very costly, not only for maintenance actions but also for lost production time. From the operators' view, it

EU POWER MIX 2000 (MW)

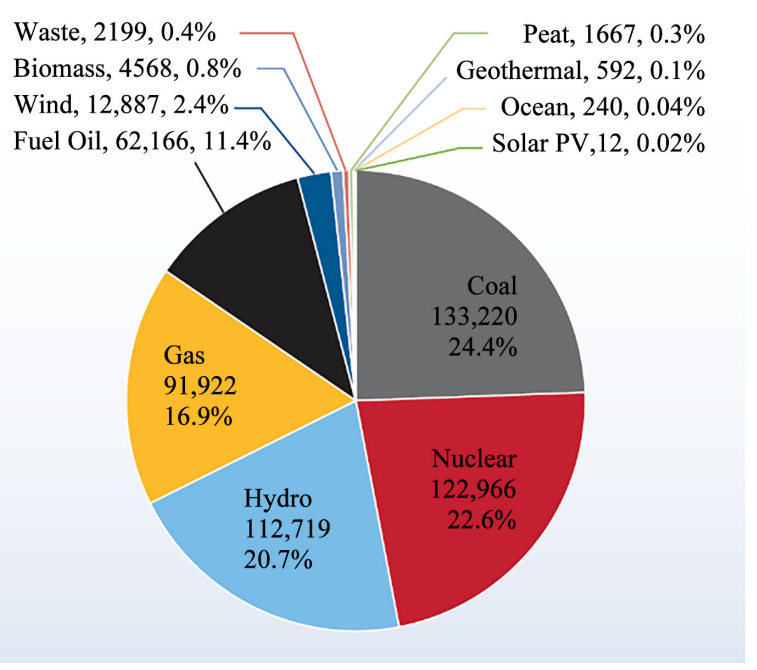

\section{EU POWER MIX 2015 (MW)}

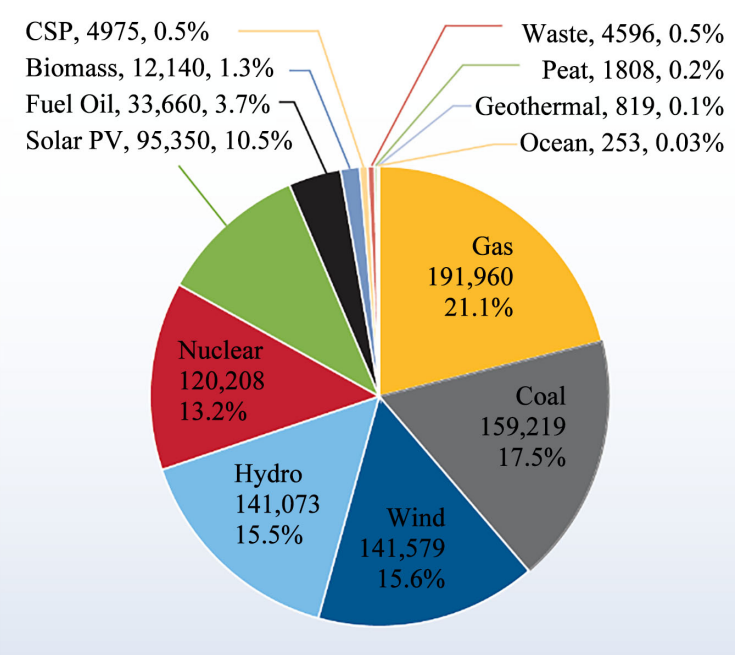

Figure 1. Comparison of EU Power Mix in 2000 and 2015 [2]. 
is, therefore, worth increasing effort spent to monitor the wind turbine condition in order to reduce unanticipated downtime and thus reduce the maintenance cost and production time loss. Therefore, prediction of faults of wind turbines as early as possible becomes the key part of condition monitoring. In the other hand, false critical alarms may cause even more cost due to lots of resources maybe used for the maintenance that is not needed.

SCADA system, which is installed with almost all wind turbines, mainly logs the performance parameters of wind turbines. It would be beneficial for the wind farm owners if the SCADA data can be analysed and interpreted automatically to predict faults early enough to help them to do the maintenance actions just when it is needed.

There are mainly two methodologies for fault prediction of wind turbines: model-based or data-based. The model-based methods require a comprehensive physical or mathematical model which is usually unavailable. Data-based methods are based on the history data and data mining technologies are used to find the relations among variables in the data. Wind turbine mathematical/physical models are normally unavailable but the data has been collected and stored via SCADA system, and thus data-based technologies are preferred [8]. There are some works in literature to use SCADA data analysis to detect faults of wind turbine components with model-based or data-driven methodologies [9] [10] [11] [12] [13], however, none of them consider to design a mechanism to avoid false warning and false alarms due to sudden changes of wind turbine running condition which the model may be not fast enough to capture these changes.

This paper describes the methodology to automatically predict incipient faults of wind turbine main bearings by analyzing SCADA data based on Artificial Neural Network (ANN), which has been implemented in EmPower ${ }^{\circledast}$ developed by Kongsberg Digital AS. The ANN model of turbine main bearing normal behaviour is established firstly and then the deviation between estimated and actual values of the parameter is calculated.The deviation is used to be an indicator of abnormal behavior of main bearing. To avoid the false warning/alarm, a time interval (i.e. a week) is used to calculate the percentage of time that the deviation is above warning/alarm threshold. In this way, incipient faults are detected in advance and false warning/alarm is avoided, and thus, only actual warnings/alarms are sent to the operator.

The remaining sections of this paper are organized as follows. Section 2 describes the principle of Artificial Neural Network (ANN). Section 3 proposes the procedure of fault prediction and warning/alarm generation. Section 4 describes how the normal behavior ANN model is established based on SCADA data. Section 5 proposes how the warning and alarm can be generated automatically based on established normal behavior ANN model. Section 6 describes how the proposed procedure to be applied in online monitoring for wind turbines and some cases are shown. Section 7 gives the conclusions and indicates some future works. 


\section{Artificial Neural Network}

ANN is a type of massively parallel computer architecture based on brain-like information encoding and processing models which exhibit brain like behaviors such as learning, association, categorization, generalization, feature extraction and optimization. It is used in cases where rules or criteria for searching an answer is not clear that is why ANN is often called black box due to that it can solve the problem but at times it is hard to explain how the problem is solved. For engineering purposes, the ANN can be thought of as a black box model which accepts inputs, processes them and produces outputs according to some non-linear transfer function [14]. There are lots of advantages of using ANN to model the multi-inputs, multi-outputs, non-linear system in literature in general [15] [16]. But for fault prediction, the most important characters are that it can deal with complicated non-linear problems effectively without the sophisticated and specialized knowledge of the real word.

In the past decades, Artificial Neural Network (ANN) has successfully been applied to both classification and regression problems. There are some works in literature applied ANN for fault classification [17] [18] in which the method can detect if the monitored component is in fault or not. In this way, the operator can only know whether the component has already been failed or not, but cannot either track the fault development or predict the fault. This paper looks the fault detection as a regression problem to estimate the relationships between key condition indicator and other performance parameters, i.e. calculating the theoretical (estimated) value of relevant parameter and deviations between measurement and this estimated value, and thus the fault can be tracked and predicted.

The learning methods of ANN can be generally classified as three categories based on that if the targets of the data are provided during the learning process, i.e. supervised learning, semi-supervised learning and unsupervised learning [15] [19]. The feed-forward neural network trained by the Levenberg-Marquardt back propagation algorithm is one of the most widely used which was proposed by Rumelhart and McCelland in 1986 [20]. A feed-forward neural network is an artificial neural network wherein connections between the units do not form a cycle. Figure 2 shows the architecture of the feed-forward network with one hidden layer trained by back propagation mechanism. The process of this network learning can be found at the literature of [15] [21] [22]. The biggest advantage is that it does not require any special mention of the features of the function to be learned which is very suitable to be applied in wind turbine fault prediction due to the unknown of function features between inputs and outputs. It has been proved that three-layer feed-forward neural network model can approach any continuous functions at any precision [23] and thus it has been selected to be implemented in Kongsberg EmPower ${ }^{\circledR}$ for automatic fault detection and prediction.

\section{Proposed Procedure of Fault Prediction}

This section describes the procedure of fault prediction based on SCADA data 
analysis and ANN, and the way to generate warning/alarm to the customer as seen in Figure 3. There are mainly four steps of proposed methodology: establishing ANN normal behaviour of monitored variable, determining the warning and alarm level based on the SCADA data with faults and trained ANN normal behaviour model, online monitoring, and determining if the warning or alarm is generated to operators for planning the maintenance actions.

Currently, the procedure is shown in Figure 3, which is integrated in EmPower ${ }^{\circledast}$, has already applied in some wind farms (Hundhammerfjellet, Havøygavlen and Smøla, etc.) for components of main bearings, gearboxes and generators bearings [24] [25] [26] [27], and the system can give early enough warning of failures to enable operators to schedule the maintenance actions. The following sections will show how this procedure works by taking main bearings as an example.

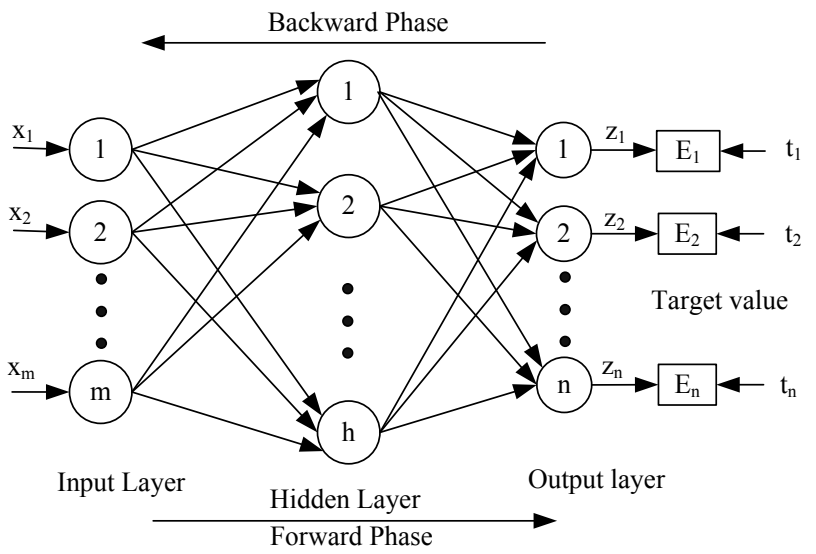

Figure 2. Feed-forward Neural Network with Single Hidden Layer [15].

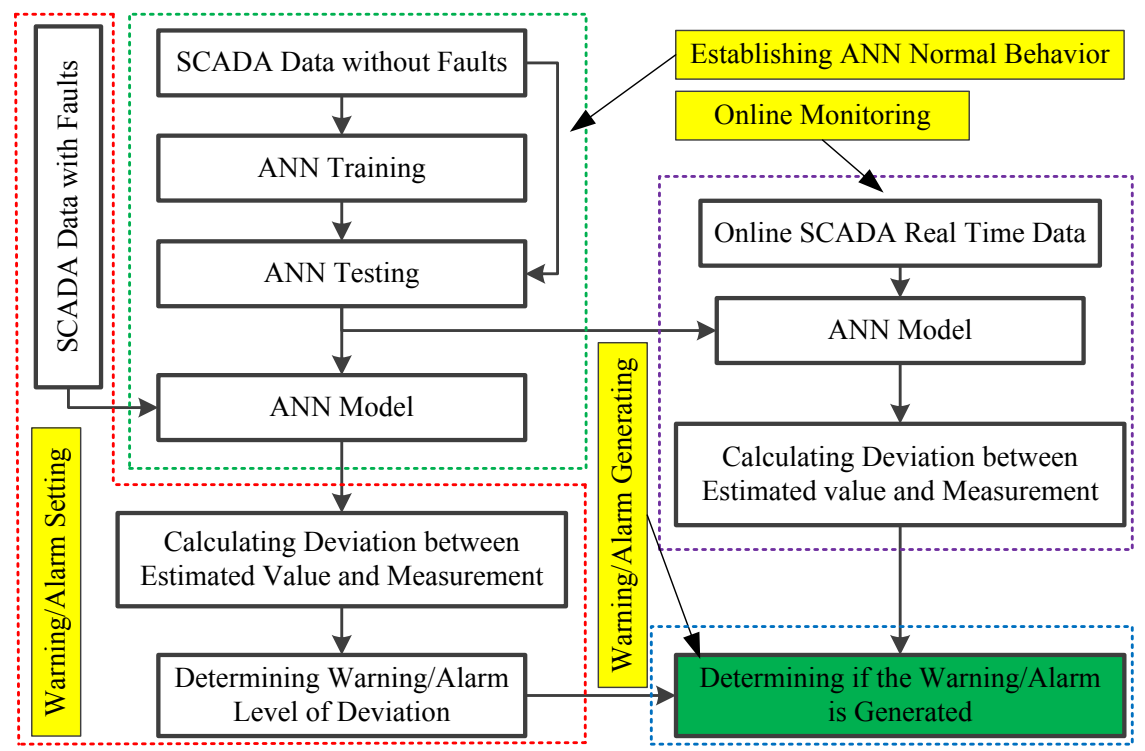

Figure 3. Procedure of fault prediction based on SCADA and ANN. 


\section{Establishing Normal Behavior Model}

SCADA data from the wind farm of Hundhammerfjellet owned by NTE-Nord-Trøndelag Elektrisitetsverk are used in this paper. Hundhammerfjellet Wind Farm is located in Nærøy, Norway and has been completed in December 2009. It has 17 wind turbines with output between 1.66 and $3.5 \mathrm{MW}$, delivered from Norwegian manufacturer Scanwind (14 turbines), Vestas (one V66) and Enercon (one E-70 2.0 MW and one E-70 2.3 MW). All SCADA data are logged in 10 minutes average. The turbines in this wind farms are direct-driven turbines (14 Scanwind turbines) without gearbox which makes the main bearings suffer most of the torque which supposed to be suffered by the gearbox, and thus, the two main bearings, especially the rear one (generator side), become the vulnerable mechanical components. Therefore, the main shaft rear bearing is taken as an example to show how the methodology works.

The temperature of main shaft rear bearing logged in SCDA system has been used as an indication of bearing condition (overheating) with fixed threshold of alarm which might be too late to avoid significant damage to the bearings. For instance, the temperature of slightly damaged bearing in winter time may not exceed the warning/alarm level just because the ambient surroundings cool the temperature down. This kind of variations of aspects makes the problem to detect the fault in time. Therefore, all relevant aspects of turbine operation should be considered to allow the abnormal condition of bearing temperatures to be detected in the context of the concurrent level of power generation, ambient temperature and so on leading to a quicker and more effective identification of abnormal behavior.

\subsection{Parameter Selection}

There are lots of variables relevant to wind turbine conditions and performance have been logged by SCADA data. Only small part of them influence the temperature of main shaft rear bearing which should be used to build the model. There is some literature to build the normal behavior model of gearbox using the relevant variables of power, nacelle temperature, cooling fan run status [9] [28] [29]. There are no works in the literature specifically for direct-driven wind turbine main shaft bearings. We, Kongsberg Renewables Technology AS, have closely cooperated with the owner of wind farms. After careful analysis of relevant parameters and discussion with the $\mathrm{O} \& \mathrm{M}$ operators, variables in Table 1 have been selected as the variables to be used to build ANN normal behavior model. We have tested the wind speed as an additional input to the model, but the result has not been improved. Therefore, the inputs and output of the model are just as Table 1.

\subsection{Training and Testing ANN Model}

The variables to be used for ANN normal behavior model learning is shown in Table 1 . The values of the variables should be as varied as possible in the learning 
Table 1. Input and Outputs of ANN Model.

\begin{tabular}{cc}
\hline Model Output & Input \\
\hline & Rear bearing temperature $(t-1)$ \\
Rear Bearing Temperature $(t)$ & Active power output $(t-1, t)$ \\
& Ambient Temperature $(t-1, t)$ \\
& Turbine speed $(t-1, t)$ \\
\hline
\end{tabular}

process which is obtained by using long enough period data with different running situations of the wind turbines. Therefore, six months from 01.01.2009 to 01.07.2009 SCADA roughly 25,920 datasets as in Figure 4 are selected with different situations of stop-restarts, high and low power production and from winter to summer time. Referring to the structure of ANN, the number of nodes in the input layer is the same as the number of inputs, i.e. 7, while the number of nodes of outputs layer is the same as the number of outputs, i.e. 1 . There is no analytical algorithm to determine the number of nodes of hidden layer but the empirical number is between one and two times of sum of numbers of inputs and outs [30]. The trial and error method is also used to find the ANN topology with the smallest mean square error and finally the structure 7-10-1 is selected.

The trained ANN model has been tested with new data together with trained data from the same healthy wind turbine. Figure 5 shows the data of inputs to the trained ANN model from 01.01.2009 to 01.07.2010 which contains both training data and new data. The turbine was stopped during the period of 15.10.2009-15.04.2010 which can be seen in the figure. In the test process, it is not as the same as training process that the measurement of turbine rear bearing temperature $(t-1)$ is not used as an input but uses previous estimated temperature $(t-1)$ instead. In this way, the abnormal temperature affecting to ANN model has been avoided, and thus, the output of ANN model, which is always normal behavior model, is theoretical temperature.

Figure 6 shows the output of rear bearing ANN model (EstimatedTemp), turbine rear bearing temperature and the deviation between these two values. The mean deviation is $0.03^{\circ} \mathrm{C}$, and the root mean square error of the deviation is $0.35^{\circ} \mathrm{C}$, which means that the model is good enough to simulate the normal behavior of turbine rear main bearing. The trend of deviation can be used to detect the development of bearing faults.

The ANN model may not be able to follow the rapid changing of the turbine running condition such as the start of the turbine. Therefore, it is normal that the deviation will increase to a high level and goes back to normal with a short time. If the warnings/alarms are generated based on the single value of deviation, there would be lots of false warnings and alarms. Therefore, long time big deviation would be better to be used to generate the warnings and alarms. The mechanism of how this work is described in Section 5.

\section{Warning/Alarm Setting}

To set the right warning and/or alarm level based on the deviation between actual 
measurement and estimated temperature, data with faults must be used. Figure 7 shows the inputs to the Normal behaviour ANN model which are SCADA data with fault component, i.e. turbine rear bearing. We, of course, cannot see any problem from the inputs variables in this figure and the expected output of the model should be the temperature without any fault. Figure 8(a) shows the estimated temperature and turbine rear bearing temperature measurement while
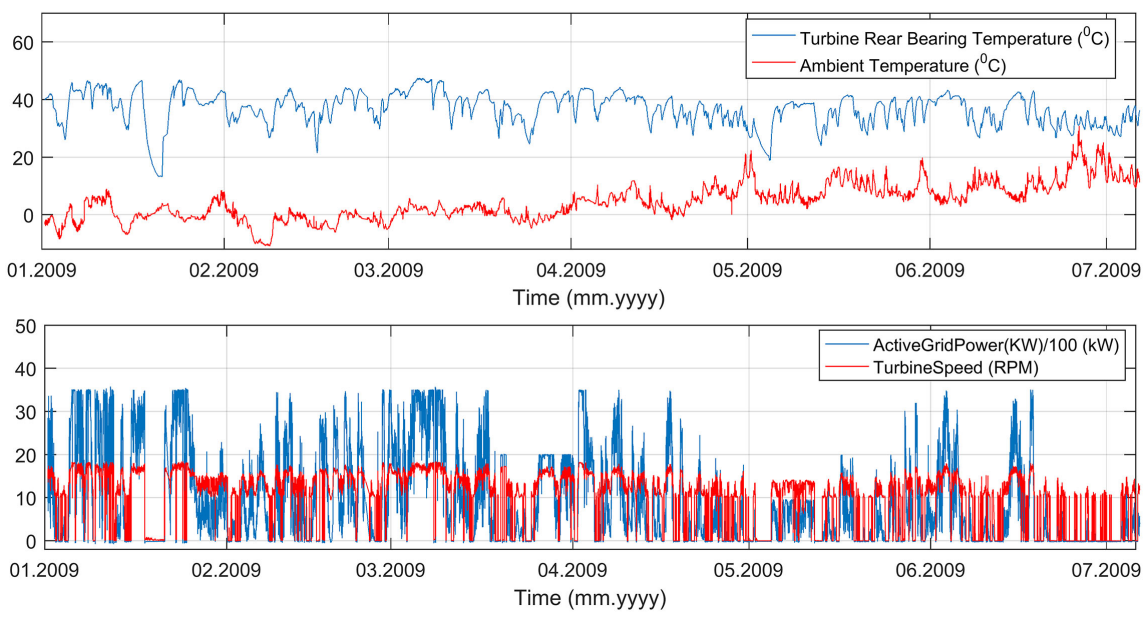

Figure 4. Neural network turbine rear bearing temperature model training data.

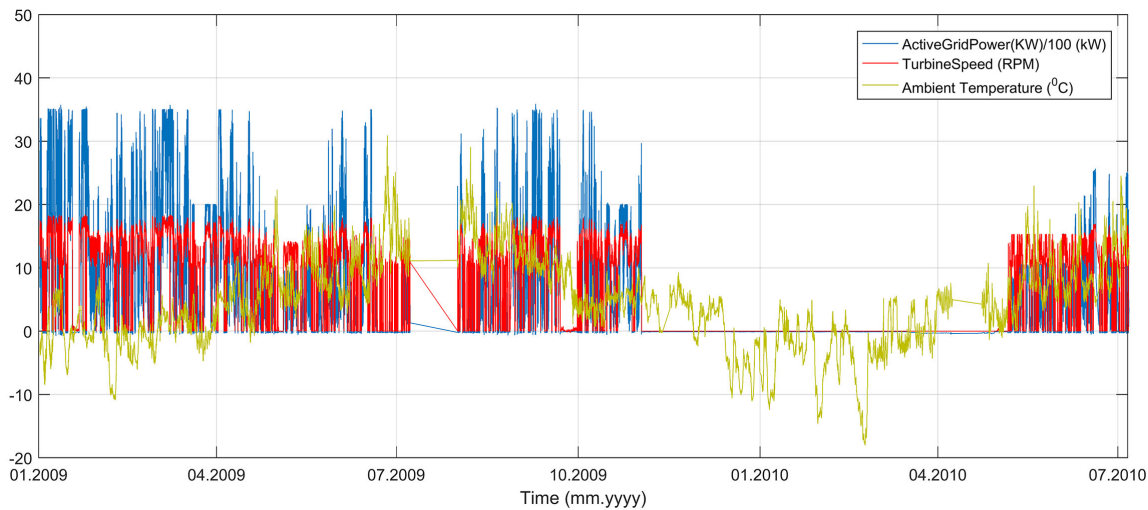

Figure 5. Rear bearing test input data.

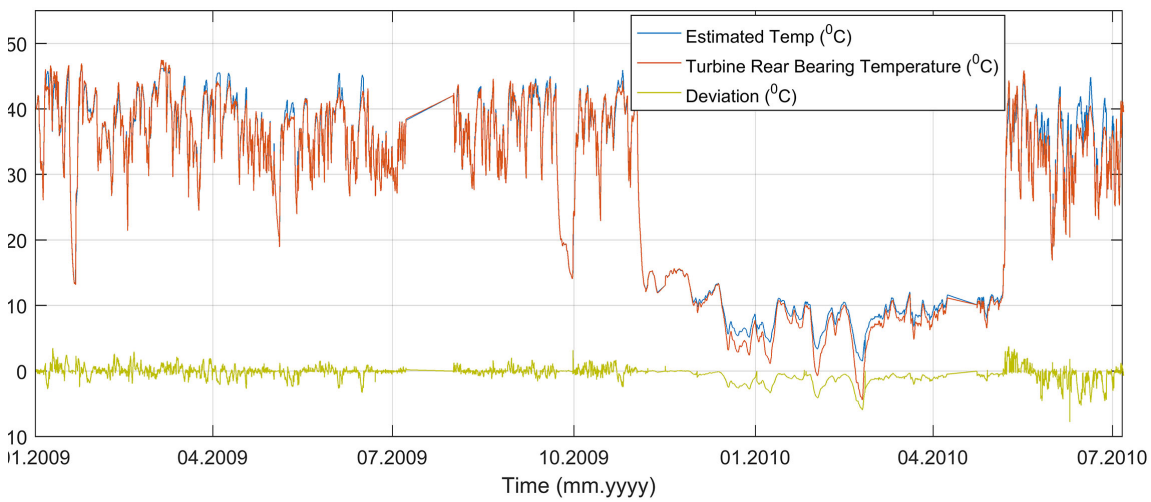

Figure 6. Rear bearing test results. 


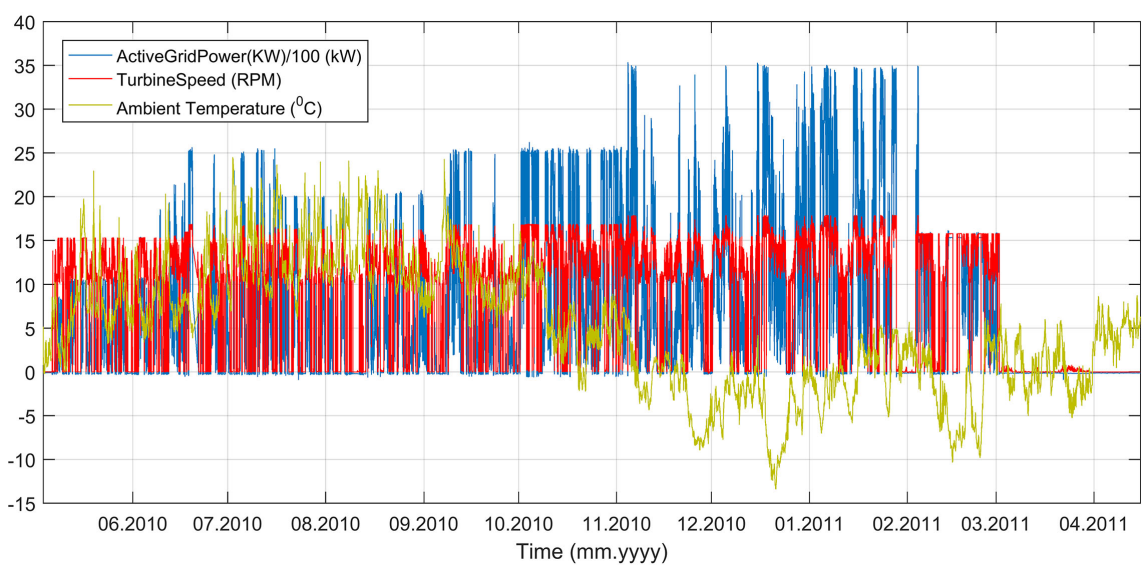

Figure 7. Warning/Alarm setting data input.

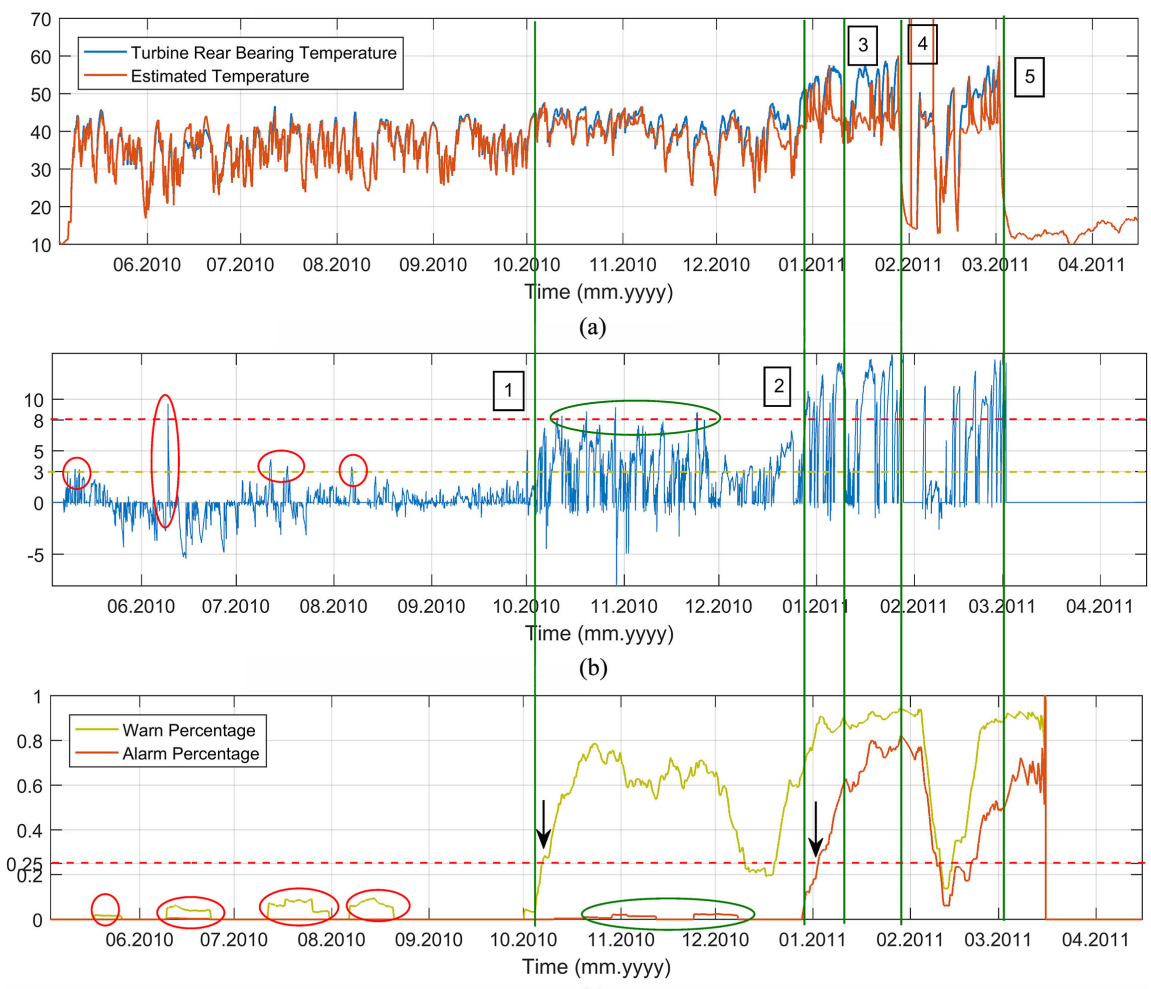

(c)

Figure 8. Warning/Alarm setting result. (a) Actual measurement and estimated temperature; (b) Deviation between estimated temperature and measurement; (c) Warn/Alarm percentage.

Figure 8(b) shows the deviation between these two. The first important deviation $\left(3^{\circ} \mathrm{C}\right)$ started at October 2010 , i.e. point (1). The deviation kept in the higher level for approximately three months and increased further to $8^{\circ} \mathrm{C}$ at point (2) where the alarm should be generated. Approximately 2 weeks later, the wind turbine was stopped due to overheat of the bearing in point (3). There are two times at point (3) and point (4) trying to fix the problem, but not successfully, and finally the wind turbine was absolutely down at point (5). 
From above analysis, the proposed methodology can provide an early warning of problems developing in the bearing before the absolute temperature becomes apparently high. However, if the $3^{\circ} \mathrm{C}$ and $8^{\circ} \mathrm{C}$ are set as fixed thresholds of the warning and alarm to generate warning and/or alarm to the operators automatically, which is the expected function from operators of the wind farms, there will be many false warnings and false alarms. Red and green circles in Figure 8(b) show the false warnings and false alarms respectively. This phenomenon is very commonly happening due to the suddenly changing of running conditions of wind turbines.

To avoid false warnings and false alarms, fixed warning/alarm thresholds cannot be used directly. Instead of setting warning/alarm at each data point, a time interval with sliding window is used to judge if the warning or alarm will be generated. The process can be described as following:

- Selecting time an interval $T_{\text {total }}$ from beginning, i.e. one week or other specific time interval.

- Finding the time with power production $T_{\text {prod }}$ in the time interval $T_{\text {total }}$.

- Finding all time when the deviation over the warning level $\left(T_{\text {warn }}\right)$ and alarm level $T_{\text {alarm }}$. The fixed warning and alarm levels are $3^{\circ} \mathrm{C}$ and alarm level $8^{\circ} \mathrm{C}$ respectively in this case.

- Calculating percentages of warning time and alarm time as following two formulas.

$$
\begin{array}{r}
\text { Warning percentage: } P_{\text {warn }}=\frac{T_{\text {warn }}}{T_{\text {prod }}} * 100 \% \\
\text { Alarm Percentage: } P_{\text {alarm }}=\frac{T_{\text {alarm }}}{T_{\text {prod }}} * 100 \%
\end{array}
$$

If there are $25 \%$ production time with deviation over fixed warning/alarm level, the system will generate warning/alarm to operator automatically. In this way, the false warning and false alarms can be completely avoided.

Figure $8(\mathrm{c})$ shows the warning/alarm settings with the above-mentioned mechanism. One week interval is selected as time duration to calculate the percentages of time over the warning and alarm level. The figure shows that all false warnings and alarms are avoided as seen in red and blue circles. Even the warning and alarm time is a little bit late compared with Figure $8(\mathrm{~b})$ in point (1) and (2) (approximately 2 - 3 days), the methodology still makes sense because it avoids lots of annoying disturbance due to the false alarm or false warning which the operator must take care of. Comparing with 4 - 5 months warning before the failure happens, 2 - 3 days delay is acceptable.

\section{Online Monitoring and Warning/Alarm Determination}

Once the normal behavior ANN model is trained and the warning/alarm is set, the proposed methodology can detect the corresponding fault of turbine rear bearing by comparing estimated and actual temperature, and furthermore, the 
warning and/or alarm can be automatically generated to the operators to enable them to have enough time to plan the maintenance actions. The EmPower ${ }^{\circledR}$ has successfully predicted the faults of wind turbine rear bearings and generated warning and alarm signals automatically to the operator. Figure 9, Figure 10 and Figure 11 show the faults predicted in three different turbines during the online condition monitoring.

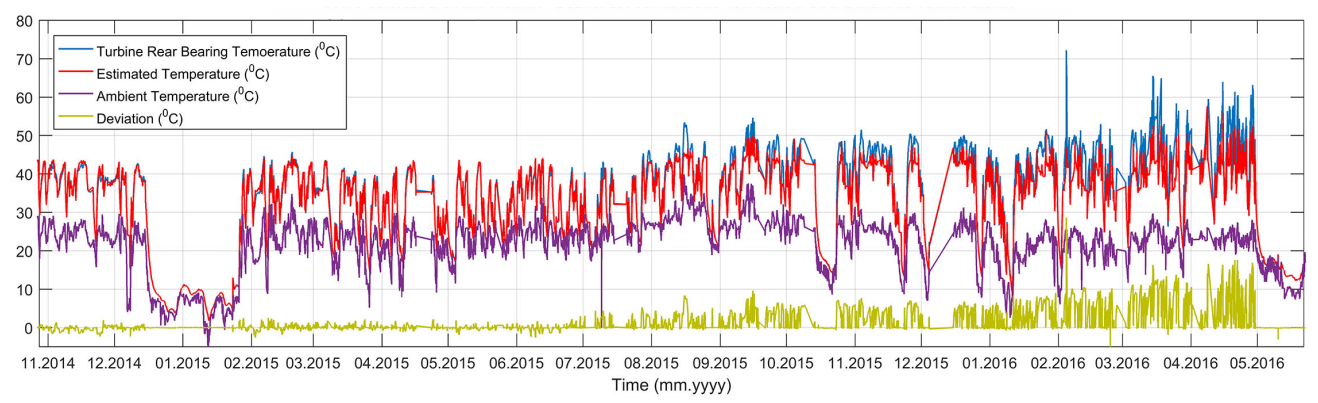

(a)

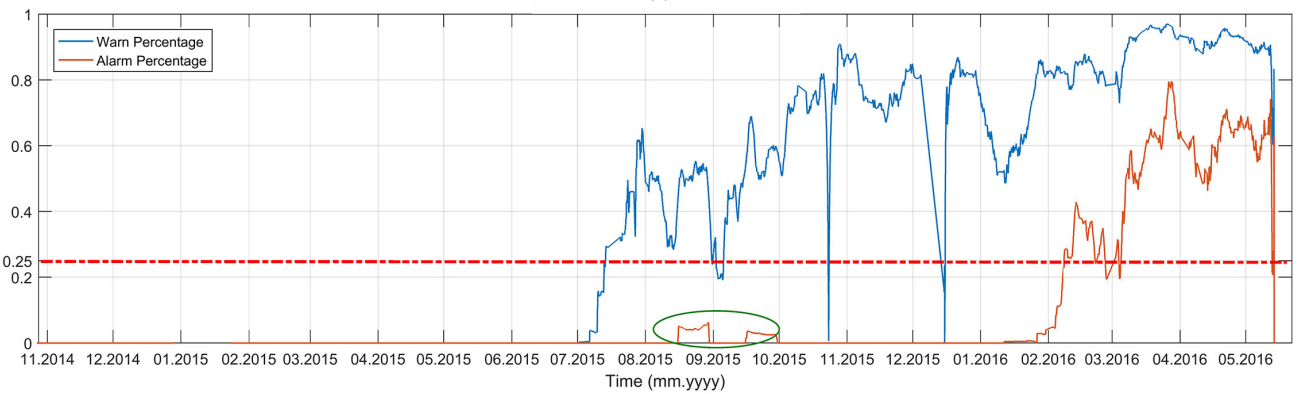

(b)

Figure 9. Online condition monitoring of turbine 3. (a) Estimated temperature, actual measurement, deviation and ambient temperature; (b) Warn/Alarm percentage.

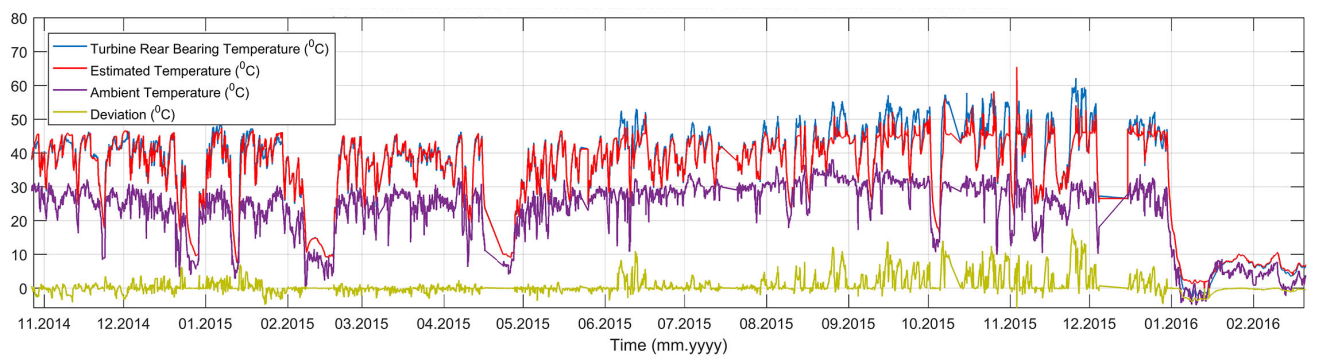

(a)

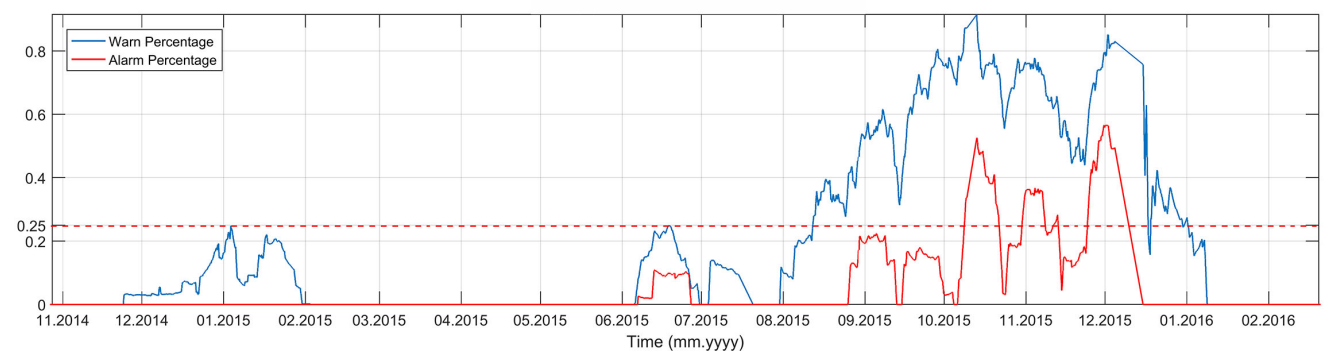

(b)

Figure 10. Online condition monitoring of turbine 15. (a) Estimated temperature, actual measurement, deviation and ambient temperature; (b) Warn/Alarm percentage. 


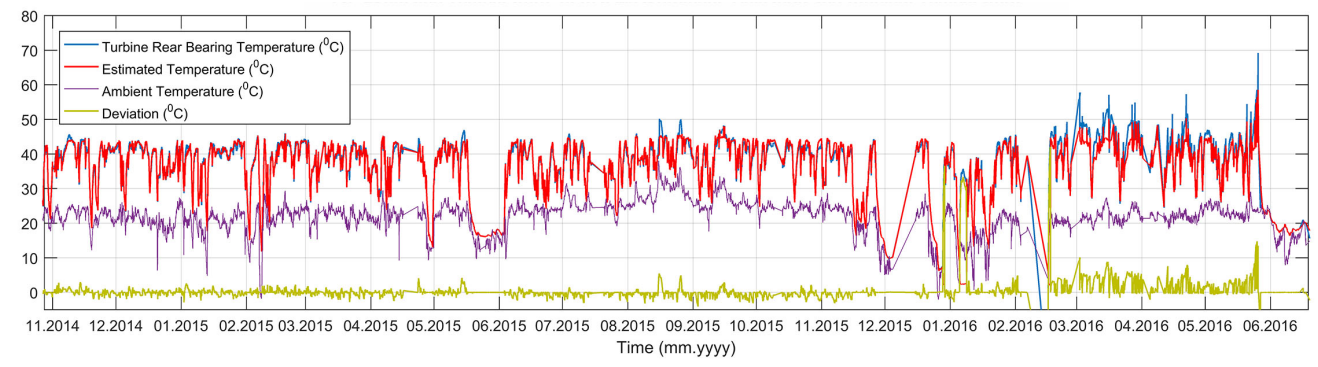

(a)

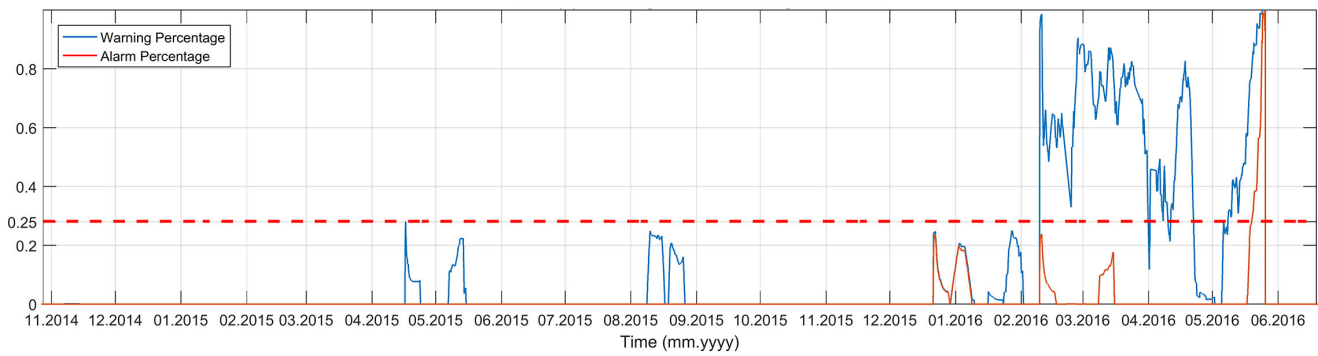

(b)

Figure 11. Online condition monitoring of turbine 10. (a) Estimated temperature, actual measurement, deviation and ambient temperature; (b) Warn/Alarm percentage.

Figure 9 shows the online condition monitoring result of turbine 3. It indicates that the warning was generated as early as 10 months, and the alarm was generated 2.5 months before failure.

Figure 10 shows the online condition monitoring result of turbine 15. It indicates that the warning was generated 4.5 months, and the alarm was generated 2.5 months before failure.

Figure 11 shows the online condition monitoring result of turbine 10. It indicates that the warning was generated 3.5 months, and the alarm was generated just 3 days before failure. We can see that the turbine rear bearing temperature increase extremely fast to very high level in very short time. ANN normal behavior model can capture this trend, but of course, can only generate a short time alarm signal.

These figures show that the time that the early warnings and alarms can be generated is varied. The expected mean values of these times should be set with a confidence level. However, the wind farms, which EmPower ${ }^{\circledR}$ applied in, just have these four cases of the rear bearing faults that are not enough for statistics. To set these expected times and their confidence level is a future work when more cases appear in these wind farms.

\section{Conclusions and Future Work}

This article proposed a methodology for fault prediction based on ANN and existing SCADA data for wind turbine components. After training, the previous output of the model becomes one of the inputs to ANN to calculate estimated/theoretical values without the effect of abnormal situations of monitored parameters and thus the deviation between estimated and actual values can be 
calculated which is used for to generate warnings and alarms. Furthermore, the mechanism of generating warning and alarm automatically to the operator has been proposed based on the deviation. A way to avoid false warning and alarm caused by sudden changing of wind turbine running condition has been also proposed. The results of online condition monitoring show that it can successfully predict the fault of wind turbine components and generate warnings and alarms in proper time before failure. In addition, the false warnings/alarms are also avoided by proposed mechanism. In this way, the operators can plan the maintenance actions when and just when they are needed in advance. Therefore, the unnecessary maintenance can be avoided and the $\mathrm{O} \& \mathrm{M}$ cost can be dramatically reduced. At the same time, downtime for maintenance has been dramatically reduced by preparation of everything before failure happen, and thus reduces the production loss.

There are some directions for future work:

EmPower ${ }^{\oplus}$ has also established the ANN normal behavior model for other components, i.e. turbine front bearings, generator bearings and gearboxes if the turbine is with a gearbox. However, no issue has founded yet for these components since the system installed. Therefore, we should keep eyes on the online condition monitoring system based on proposed methodology to see if proposed procedures can be also functioning for these components.

Currently, the percentage of time that the deviation is over warning, or alarm level is just based on the observation of the data. The systematic way should be developed in the future to find these percentage levels.

The warnings can be given $3-10$ months before failure while the alarms can be given from some days to 2 months before failure from the cases we have so far. In the future, the expected mean time the warning and alarm can be given should be used and the standard deviation should also be given based on a statistical result. Since only four cases available, the statistical result cannot be concluded. We should keep the system running and keep eyes on it to have enough cases to be able to have the statistical conclusion.

\section{Acknowledgements}

This paper is supported by research project Windsense-Add-on Instrumentation System for Wind Turbines which is financially supported by the project participants and Research Council of Norway.

\section{References}

[1] GWEC (2016) Global Wind Statistics 2015. http://www.gwec.net/wp-content/uploads/vip/GWEC-Global-Wind-2015-Report April-2016_22_04.pdf

[2] EWEA (2016) Wind in Power-2015 European Statistics. https://www.ewea.org/fileadmin/files/library/publications/statistics/EWEA-AnnualStatistics-2015.pdf

[3] Blanco, M.I., Krohn, S., Morthorst, P.-E. and Awerbuch, S. (2009) The Economics 
of Wind Energy.

http://www.ewea.org/fileadmin/ewea_documents/documents/publications/reports/ Economics_of_Wind_Main_Report_FINAL-lr.pdf

[4] EWEA (2014) Wind Energy Scenarios for 2020.

[5] Alberici, S., Boeve, S., Van Breevoort, P., Deng, Y., Förster, S., Gardiner, A., van Gastel, V., Grave, K., Groenenberg, H., de Jager, D., Klaassen, E., Pouwels, W., Smith, M., de Visser, E., Winkel, T. and Wouters, K. (2014) Subsidies and Costs of EU Energy.

https://ec.europa.eu/energy/sites/ener/files/documents/ECOFYS\%202014\%20Subsi dies\%20and\%20costs\%20of\%20EU\%20energy_11_Nov.pdf

[6] Carroll, J., McDonald, A. and McMillan, D. (2016) Failure Rate, Repair Time and Unscheduled O \& M Cost Analysis of Offshore Wind Turbines. Wind Energy, 19, 1107-1119. https://doi.org/10.1002/we.1887

[7] Dinwoodie, I., McMillan, D., Revie, M., Lazakis, I. and Dalgic, Y. (2013) Development of a Combined Operational and Strategic Decision Support Model for Offshore Wind. Energy Procedia, 35, 157-166. https://doi.org/10.1016/j.egypro.2013.07.169

[8] Nassim, L. (2011) Support Vector Machines for Fault Detection in Wind Turbines. In: Sergio, B., Ed., Proceedings of 18 th IFAC World Congress, Milano, 7067-7072.

[9] Zaher, A., McArthur, S.D.J., Infield, D.G. and Patel, Y. (2009) Online Wind Turbine Fault Detection through Automated SCADA Data Analysis. Wind Energy, 12, 574-593. https://doi.org/10.1002/we.319

[10] Borchersen, A.B. and Kinnaert, M. (2016) Model-Based Fault Detection for Generator Cooling System in Wind Turbines Using SCADA Data. Wind Energy, 19, 593-606. https://doi.org/10.1002/we.1852

[11] Feng, Y., Qiu, Y., Crabtree, C.J., Long, H. and Tavner, P.J. (2011) Use of SCADA and CMS Signals for Failure Detection and Diagnosis of a Wind Turbine Gearbox. European Wind Energy Conference \& Exhibition, Brussels, 14-17 March 2011, 1-9.

[12] Zhang, Z. and Wang, K. (2014) Wind Turbine Fault Detection Based on SCADA Data Analysis Using ANN. Advanced Manufacturing, 2, 70-78. https://doi.org/10.1007/s40436-014-0061-6

[13] Zhang, Z. (2012) Comparison of Data-Driven and Model-Based Methodologies of Wind Turbine Fault Detection with SCADA Data. Sci. Proc. EWEA Annu. Conf., Barcelona, 172-176.

[14] Zaknich, A. (2003) Neural Networks for Intelligent Signal Processing. World Scientific, Singapore. https://doi.org/10.1142/5220

[15] Wang, K. (2005) Applied Computational Intelligence in Intelligent Manufacturing Systems. Advanced Knowledge International Pty Ltd., Adelaide.

[16] May, R., Dandy, G. and Maier, H. (2011) Artificial Neural Networks-Methodological Advances and Biomedical Applications. InTech, London.

[17] Saravanan, N. and Ramachandran, K.I. (2010) Incipient Gear Box Fault Diagnosis Using Discrete Wavelet Transform (DWT) for Feature Extraction and Classification Using Artificial Neural Network (ANN). Expert Systems with Applications, 37, 4168-4181. https://doi.org/10.1016/j.eswa.2009.11.006

[18] Momoh, J. and Button, R. (2003) Design and Analysis of Aerospace DC Arcing Faults Using Fast Fourier Transformation and Artificial Neural Network. Power Engineering Society General Meeting, Toronto, 13-17 July 2003, 788-793. https://doi.org/10.1109/PES.2003.1270407

[19] Lee, D.-H. (2013) Pseudo-Label: The Simple and Efficient Semi-Supervised Learn- 
ing Method for Deep Neural Networks. Challenges in Representation Learning, Atlanta, 1-6.

https://www.kaggle.com/blobs/download/forum-message-attachment-files/746/pse udo_label_final.pdf

[20] Rumelhart, D.E., Hinton, G.E. and Williams, R.J. (1986) Learning Internal Representations by Error Propagation. In: Rumenhart, D.E. and McCelland, J.L., Eds., Parallel Distributed Processing. Explorations in the Microstructure of Cognition, MIT Press, Cambridge, 318-362.

[21] Robinson, A.J. (1994) An Application of Recurrent Nets to Phone Probability Estimation. IEEE Transactions on Neural Networks, 5, 298-305. https://doi.org/10.1109/72.279192

[22] Marquardt, D.W. (1963) An Algorithm for Least-Squares Estimation of Nonlinear Parameters. Journal of the Society for Industrial and Applied Mathematics, 11, 431-441. https://doi.org/10.1137/0111030

[23] Zhang, Z., Wang, Y. and Wang, K. (2013) Intelligent Fault Diagnosis and Prognosis Approach for Rotating Machinery Integrating Wavelet Transform, Principal Component Analysis, and Artificial Neural Networks. The International Journal of Advanced Manufacturing Technology, 68, 763-773.

https://doi.org/10.1007/s00170-013-4797-0

[24] Statkraft Installs Kongsberg Digital's EmPower at Smøla, Kongsb. Digit. AS. (2016). https://kongsberg.com/en/kog/news/2016/june/statkraft\%20installs\%20kongsberg\% 20digitals\%20empower\%20at\%20smola/

[25] Arctic Wind Chooses Kongsberg EmPower, Kongsb. Renewables Technol. AS. (2015).

https://www.kongsberg.com/en/kongsberg-digital/renewables\%20and\%20utilities/n ews/2015/june/arctic-wind-chooses-kongsberg-empower/

[26] Statoil chooses Kongsberg EmPower for Hywind Demo, Kongsb. Digit. AS. (2016). https://kongsberg.com/en/kog/news/2016/may/statoil\%20chooses\%20kongsberg\%2 0empower\%20for\%20hywind\%20demo/

[27] Going Renewables, Kongsb. Digit. AS. (2015). http://stories.kongsberg.com/content/going-renewable

[28] Garcia, M.C., Sanz-Bobi, M.A. and del Pico, J. (2006) SIMAP: Intelligent System for Predictive Maintenance. Application to the Health Condition Monitoring of a Wind Turbine Gearbox. Computers in Industry, 57, 552-568. https://doi.org/10.1016/j.compind.2006.02.011

[29] Zaher, A.S. and McArthur, S.D.J. (2007) A Multi-Agent Fault Detection System for Wind Turbine Defect Recognition and Diagnosis. 2007 IEEE Lausanne Power Tech, Lausanne, 1-5 July 2007, 22-27.

[30] Karsoliya, S. (2012) Approximating Number of Hidden Layer Neurons in Multiple Hidden Layer BPNN Architecture. International Journal of Engineering Trends and Technology, 3, 714-717. 